\title{
Yersiniosis - a zoonotic foodborne disease of relevance to public health
}

\author{
Agata Bancerz-Kisiel', Wojciech Szweda' \\ 1 Department of Epizootiology, Faculty of Veterinary Medicine, University of Warmia and Mazury in Olsztyn, Poland
}

Bancerz-Kisiel A, Szweda W. Yersiniosis - a zoonotic foodborne disease of relevance to public health. Ann Agric Environ Med. 2015; 22(3): 397-402. doi: 10.5604/12321966.1167700

\begin{abstract}
I Abstract
Introduction. $Y$. enterocolitica is the causative agent of yersiniosis - a foodborne zoonosis with substantial importance to public health. Y. enterocolitica is widespread in the environment and animal populations, posing a potential source of infection to humans.

Objective. Presentation of yersiniosis as a zoonotic foodborne disease of relevance to public health.

State of knowledge. Swine play an important role as a reservoir of $Y$. enterocolitica and insufficiently thermally processed pork is the main source of infection to humans. The correlation between strains isolated from pigs and from clinical cases of human yersiniosis has been sufficiently proven. Yersiniosis usually appears with gastrointestinal disturbances in children, whereas in adults it manifests in a pseudo-appendix form. The extra-enteric form of yersiniosis is rare. Classical bacteriological methods used for classifying $Y$. enterocolitica as pathogenic does not take into account the new aspects of the pathogenesis of yersiniosis. The examples are biotype $1 \mathrm{~A}$ strains, commonly regarded as non-pathogenic, although they are increasingly often isolated from clinical cases of yersiniosis. Molecular methods seem much more effective and accurate in the diagnostic. New diagnostic tools such as real-time PCR, allows not only qualitative examination, but also quantitative evaluation of genes expression level, or single nucleotide polymorphism detection.

Conclusions. Yersiniosis is an important food-borne zoonosis with wide range of clinical symptoms. Considering the fact that pork is the main source of infection for humans, public information campaigns seems to be an important element of the preventive measures against $Y$. enterocolitica infections.
\end{abstract}

\section{Key words}

Yersinia enterocolitica, yersiniosis, foodborne zoonosis

\section{INTRODUCTION AND OBJECTIVE}

Yersinia (Y.) enterocolitica is a major foodborne pathogen causing yersiniosis. A total of 7,017 confirmed cases of yersiniosis were reported in the European Union in 2011, corresponding to an increase by $3.5 \%$ compared with 2010 [1]. In Poland in 2011, a total of 257 yersiniosis cases were reported, the incidence rate was 0.67 per 100,000 inhabitants [2]. In 2012, the number of confirmed yersiniosis cases has decreased to 231, with an incidence rate of 0.6 per 100,000 inhabitants [3].

Y. enterocolitica is widespread in the environment and animal populations, posing a potential source of infection to humans. The main reservoir of $Y$. enterocolitica strains pathogenic for human are pigs [4]. Contaminated pork and pork products are believed to be the most important source of infection [5]. Eating or tasting raw or medium done pork is a significant risk factor for pathogenic Y. enterocolitica infection [4]. Foodborne outbreaks are also associated with consumption of untreated water, contaminated milk (unpasteurized or inadequately pasteurized), tofu or bean sprouts [6]. Person-to-person transmission of the pathogen is rare, but contamination of food by infected food handlers and nosocomial infections have been reported [6].

$Y$. enterocolitica is a heterogeneous group of bacteria. The species has been divided into 2 subspecies (Y. enterocolitica

Address for correspondence: Agata Bancerz-Kisiel, Department of Epizootiology, Faculty of Veterinary Medicine, University of Warmia and Mazury in Olsztyn, Oczapowskiego 13, 10-719 Olsztyn, Poland

E-mail: a.bancerz-kisiel@uwm.edu.pl

Received: 03 November 2014; accepted: 26 November 2014 subsp. enterocolitica and subsp. palearctica) [7]. From among the 6 known biotypes, the strains belonging to biotypes $1 \mathrm{~B}$ and 2-5 Y. enterocolitica are considered to be pathogenic for animals and humans $[4,5,6]$. Biotype $1 \mathrm{~A}$ strains without the classical virulence markers are regarded as non-pathogenic [8]. However, according to some authors, biotype $1 \mathrm{~A}$ has a pathogenic potential [9], what suggest that the way of pathogenicity defining based only on biotype determination needs to be changed. Generally, the pathogenicity of Y. enterocolitica depends on the presence of several genes, known as virulence markers. These genes facilitate bacteria to enter a susceptible organism, colonize it, evade the immune system and grow under unfavorable conditions [10].

The virulence marker most typical of $Y$. enterocolitica is pYV (Yersinia virulence plasmid), where several genes directly related to pathogenicity are located [10]. The yadA gene encodes the production of the YadA (Yersinia adhesin) protein - component of fimbriae and a fibrous membrane on the surface of bacterium, which mediates the binding of bacteria to HEp-2 cells (Human Epithelial cells). The yop genes encode the production of Yops (Yersinia outer membrane proteins) - regulatory proteins, which determine the resistance of bacteria to local immune mechanisms. The $y s c$ gene encodes the production of Ysc proteins - Yersinia secretion complex. virF is responsible for production of transcriptional activator of the Yersinia virulence regulon $[6,10]$. pYV-bearing $Y$. enterocolitica strains are also characterized by a type III secretion system (TTSS) and the presence of high pathogenicity island (HPI) [6].

Apart from the markers located on the pYV, Y. enterocolitica possess chromosomal markers, much more genetically 
stable than plasmid markers [11]. One of them is the ail gene, which encodes the Ail (attachment-invasion locus) protein production, allowing bacteria to adhere and enter the eukaryote cells, induce their resistance to antibodies and the complementary system $[6,11]$. The inv gene encodes the invasin production that binds bacteria to mammalian cells via surface integrins of the host cell. The fimbrial protein $\mathrm{Myf}$ A (mucoid Yersinia factor/fibrillae A) and Yst enterotoxin (Yersinia-stable toxin) are produced as a result of myf and $y$ st genes expression, respectively $[6,11]$. Currently, YstI (A, $\mathrm{B}$ and $\mathrm{C}$ ) and recently discovered, so far poorly investigated YstII enterotoxins are known [12]. Interestingly, the majority of biotype 1A strains have the $y s t B$ gene, encoding YstB enterotoxin production - probably the main cause of diarrhea in clinical cases of yersiniosis caused by Y. enterocolitica biotype 1A strains $[13,14]$.

The objective of the paper is to present yersiniosis as a zoonotic foodborne disease of relevance to public health.

\section{STATE OF KNOWLEDGE}

In the epidemiology of yersiniosis, swine play an important role as a reservoir of $Y$. enterocolitica $[4,5,6]$. The correlation between strains isolated from pigs and those which produce clinical signs in humans has been sufficiently proven [15]. According to Fosse et al. [16], Salmonella spp., Y. enterocolitica and Campylobacter spp. were the 3 hazards most frequently reported in human clinical cases related to the consumption of pork, as well as Y. enterocolitica and Clostridium perfringens, the 2 main hazards identified in pork carcasses. It seems that determining the source of infection by testing for a carrier state in pigs is as important as diagnosing the disease in humans. In many countries, there have also been attempts to prevent any contact of swine carcasses with the tonsils and gastrointestinal content of slaughtered animals, and to systematically disinfect carcass cutting areas to minimize the risk of carcass contamination with Y. enterocolitica [17].

Food products that contain pork or pork-derived ingredients should be subjected to sanitary control [17]. Considering the fact that insufficiently thermally processed pork is the main source of infection to humans [5], raising awareness of the consumers to the potential risk of the consumption seems to be an important element of the prevention of Y. enterocolitica infections. At low temperatures, which are the optimal environment for Y. enterocolitica growth, the bacteria may produce a heat stable enterotoxin which is resistant to $121^{\circ} \mathrm{C}$ for 30 minutes and at $4^{\circ} \mathrm{C}$ and low $\mathrm{pH}$ retain their properties for up to several months [18]. Y. enterocolitica, as a typical psychrophil, multiplies in a food (neutral $\mathrm{pH}$, stored at $5^{\circ} \mathrm{C}$ ) from $10 / \mathrm{mL}$ to $2.8 \times 10^{7} / \mathrm{mL}$ in 5 days [19]. In food products kept in a freezer (at app. $-18^{\circ} \mathrm{C}$ ) it retains pathogenic properties for up to several months, which presents a serious risk to consumers [20]. Wherefore, washing raw fruits and vegetables, consuming only pasteurized milk and dairy products, washing hands thoroughly with warm water and soap before and after touching any raw meat products, are some of the prevention methods. Proper cleaning of all surfaces and equipment before and after food preparation prevents cross- contamination from microorganisms. Thus, good hygiene should be practiced during food processing and food preparation.
It should be emphasized that wild wild boars, red deer, roe deer and birds could also be a vector of Y. enterocolitica. The presence of potentially pathogenic $Y$. enterocolitica in wild boar, deer, roe deer and wild ducks creates a real epidemiologic risk $[21,22,23]$. The specific method of obtaining game animals in Poland (i.e. immediate evisceration) presents a risk of environmental contamination with Y. enterocolitica and its further spread. The direct contact between hunters and the eviscerated gastrointestinal tract creates a potential risk of infection. Additionally, refrigerating conditions in which carcasses are stored may facilitate bacterial growth, which seems particularly worrying in the case of free-living ruminants whose meat, similar to beef, may be consumed raw.

In humans, the clinical symptoms of yersiniosis appear most commonly as gastrointestinal disturbances, such as enteritis, enterocolitis and gastroenterocolitis accompanied by fever and severe, often bloody, diarrhea [24]. Vomiting and abdominal pain lasting for 1-3 weeks are also observed [25]. These forms are especially severe in children under 5 years of age and may be sporadic, familiar, or epidemic with a varied degree of severity $[25,26]$. In Poland in 2012, 201 cases of intestinal yersiniosis were observed [3]. No deaths related to the disease were reported, but $61.9 \%$ of patients were hospitalized. Intestinal yersiniosis was manifested mostly by the following symptoms: diarrhoea (87\%), fever (76\%), abdominal pain (47\%) and vomiting (31\%). The most affected group in intestinal infections were children younger than 4 years -145 cases ( $72 \%$ of all cases) [3]. In the course of chronic yersiniosis, necrotic enteritis and a nodular-like form of purulent mesenteric lymphadenitis may be seen, even in neonates $[25,26]$. Pseudo-appendix forms most often affect adults but may also occur in children, they appear with acute ileitis or purulent, reticulocytic mesenteric lymphadenitis, often misdiagnosed as appendicitis [27].

The extra-enteric form of yersiniosis is very rare and affects the skin, throat, lungs, liver and kidneys. The role of Y. enterocolitica in Reiter's syndrome has also been confirmed. In Poland, erythema nodosum, induced by Y. enterocolitica, constitutes over $20 \%$ of all erythema cases and usually affects women over 20 years old $[25,26]$. Articular forms are generally defined as reactive polyarthritis which occurs few days after initial gastrointestinal symptoms and may persist for several weeks or months [28]. In Poland in 2012, the extraintestinal form of infection was more common than in 2011 (19 cases), and usually involved symptoms from the osteoarticular system, noted in $90 \%$ of patients [3]. Although new forms of the disease, including autoimmune disorders, have been recently detected - Wang et al. [29] suggested that $Y$. enterocolitica is involved in the pathogenesis of Grave's disease through a mechanism of molecular mimicry.

One of the most severe forms of yersiniosis is sepsis caused by $Y$. enterocolitica bioserotype 1B/O:8. This bioserotype had been thought typical for the USA and Japan, although since 2004 infections with $Y$. enterocolitica bioserotype 1B/O:8 have been recorded in Poland [30]. The reason for increased interest in bioserotype $1 \mathrm{~B} / \mathrm{O}: 8$ is the fact that it is the most pathogenic representative of Y. enterocolitica species. $\mathrm{LD}_{50}$ (median lethal dose) is $1 \times 10^{5,4} \mathrm{cfu} / \mathrm{ml}$, whereas the analogous dose for bioserotype $4 / \mathrm{O}: 3$ is $3.5-5 \times 10^{9} \mathrm{cfu} / \mathrm{ml}$. The first strain of $1 \mathrm{~B} / \mathrm{O}: 8$ was isolated in Poland from the lymph node of a 38-year-old woman with hepatic cirrhosis [30]. In a serum sample, the high level of IgA, IgG and IgM antibodies against LPS of Y. enterocolitica O:8 and Yops were 
diagnosed by ELISA and western blot. The serological and bacteriological investigations for yersiniosis performed in the next 4 years showed that 2004 inaugurated a dramatic increase of $Y$. enterocolitica O:8 infections in Poland [30]. In 2004-2006, there were 2 cases of yersiniosis caused by bioserotype 1B/O:8, while in 2007 this number reached 11 , and in the first half of 2008 it was as high as 23 cases. According to Rastawicki et al. [31], there was seasonal pattern of Y. enterocolitica 1B/O8 infections in Poland during 20082011. A large increase in incidence was observed in the second quarter and a decrease in the third quarter of each year. Such seasonal changes were not seen in infections caused by the other enteropathogenic Yersinia bioserotypes. However, in comparison to previous years, the total number of yersiniosis caused by serotype 0:8 has now significantly decreased from 55 cases in 2011 to 3 cases in 2012 [3].

The septic form is also seen after the administration of blood, blood products or dialysis fluids stored at low temperature $\left(4^{\circ} \mathrm{C}\right)$, in which $Y$. enterocolitica rods may grow. This form of yersiniosis is very severe and fatal in over $50 \%$ of cases [32], persisting with hepatic and splenic ulcers, pneumonia, osteomyelitis, septic arthritis, meningitis or pericarditis. Peracute sepsis caused by Y. enterocolitica infection has also been observed, especially in patients with different forms of anaemia [33], and in adults with severe immunosuppression (e.g. AIDS), hepatic cirrhosis, diabetes and in alcoholics.

Despite the lack of the identifiable virulence markers in biotype 1A strains, these bacteria are often isolated not only from healthy individuals, but also from patients with gastrointestinal complaints and evoke human diseases with symptoms indistinguishable from those caused by pathogenic biotypes $[6,14]$. Endoscopic examinations of patients suffering from yersiniosis caused by biotype $1 \mathrm{~A}$ have not demonstrated any ulcerative or inflammatory lesions, which suggests that the presented symptoms are mainly associated with the production of enterotoxin YstB [34]. This was confirmed by Rammamurthy et al. [14], who demonstrated that $88.9 \%$ of $Y$. enterocolitica biotype $1 \mathrm{~A}$ strains isolated from clinical cases of yersiniosis caused accumulation of fluids in the intestines in a suckling mouse bioassay, indicating the toxigenic potential of the tested strains. In addition, a minimal dose of purified YstB enterotoxin ( $0.4 \mathrm{pmol})$ is much lower than an analogous dose of YstA enterotoxin $(7.6 \mathrm{pmol})$, which indicates its powerful action in the lumen [14].

The ability to persist in the body for a long time with alternate periods of acute symptoms and remissions is a typical feature of 1A biotype infections [34]. Lack of predisposed age group has been also observed, because the infections with $1 \mathrm{~A}$ biotype may affect humans of all ages [34]. Sepsis and death are very rare and only one fatal case has been described in Bangladesh in a patient who died due to a mixed infection Y. enterocolitica with Shigella boydii [34]. Although biotype $1 \mathrm{~A}$-associated disease cases are sporadic, two outbreaks of gastrointestinal infection have been recently reported. The first nosocomial outbreak due to Y. enterocolitica bioserotype 1A/O:5, which involved 9 patients in Canada, was reported by Ratnam et al. in 1982 [35]. The second outbreak in 1990 was caused by $Y$. enterocolitica bioserotype 1A/O:10, isolated from 19 pediatric patients in a hospital in England [36]. McNally et al. [37] even suggest that biotype 1A strains are becoming the predominant pathogenic agent of yersiniosis (58\% of the reported cases) in Commonwealth of Nations countries from the end of the $20^{\text {th }}$ century, surpassing O:3/4 strains. A recent case-control study of diarrheic patients in Finland also demonstrated a majority of Y. enterocolitica biotype 1A [4]. Hence, Y. enterocolitica biotype 1A strains represent a rapidly emerging group of human pathogens.

In animals, Y. enterocolitica infections are most often asymptomatic; however, in clinical cases, acute or chronic diarrhea, possibly with blood, and with inflammatory lesions in the intestines are noticed. Yersiniosis may also appear as sepsis with suppurative lesions in the internal organs, skin lesions (i.e. erythema), arthritis or mesenteric lymphadenitis and reproductive disorders [38]. Research reports indicate that pigs are a predominant reservoir of Y. enterocolitica strains pathogenic for humans. In this species, clinical symptoms of yersiniosis are rarely observed, excluding diarrhea, generally seen in young animals up to 8 weeks of age [38]. Companion animals are becoming an increasingly important factor in the epidemiology of Y. enterocolitica infections in humans [39]. Dogs, thought to be asymptomatic carriers may be affected with enteritis accompanied by weakness, inappetence, bloody diarrhea, vomiting, arrhythmia, and sometimes jaundice or respiratory disorders, leading to death $[38,39]$. Yersiniosis accompanied by gastrointestinal disturbances have also been reported in cats [39]. Cases of familiar epidemic yersiniosis have been recently reported and attributed to very close contact, especially of young children, with infected domestic animals [39].

The symptomatic diversity of yersiniosis makes it very difficult to diagnose based only on a clinical picture. Laboratory examinations seem to be necessary for a correct diagnosis and subsequent treatment. The procedure of analyzing bacteriological samples for Y. enterocolitica does not diverge from standard procedures used for isolation and identification of other enteric rods. Blood, faeces, peritoneal fluid, articular exudate samples, abscess material, throat swabs and intra-operatively excised mesenteric lymph nodes are collected for bacteriological examinations [25].

In Poland, bacteriological investigations are based on cultures performed according to PN-EN ISO 10273:2005 standard [40]. Two types of liquid media are used: broth with irgasan ${ }^{\mathrm{Tm}}$, ticarcillin and potassium chloride - ITC (so-called warm culture, 48 hours at $25^{\circ} \mathrm{C}$ ) and on broth with peptone, sorbitol and bile salts - PSB (so-called cold culture, at $22^{\circ} \mathrm{C}$ to $25^{\circ} \mathrm{C}$ for $48-72$ hours with shaking, or for 5 days without shaking). Two-pathway culturing is associated with the specificity of this pathogen and ability to grow at low temperatures. Scientific reports, including own studies, suggest extending the cold culture to 3 weeks with a simultaneous reduction of temperature to $4^{\circ} \mathrm{C}[21,22,23]$, which increases the likelihood of isolating $Y$. enterocolitica biotype 1A strains. Further steps, culturing on CIN selective medium (agar with cefsulodin, irgasan ${ }^{\text {mat }}$ and novobiocin) and SSDC (Salmonella/Shigella agar with sodium deoxycholate and calcium chloride), as well as biochemical differentiation, are identical for both types of culture [40]. Time pending for a result of bacteriological examination depends on the type of culture and ranges from app. 1 week for the warm culture up to a month for the cold culture. The biotype determination of the examined strains is also made in accordance with the PNEN ISO 10273:2005 standard based on trehalose, xylose and aeskulin fermentation and the detection of pyrazinamidase, Tween esterase and indol production [40]. 
Serological diagnostics of yersiniosis consists of the following assays: tube agglutination, passive agglutination, immunofluorescence, immunoenzymatic, radioimmune or western-blotting with the antigens being whole or disintegrated bacterial cells, or lipopolysaccharides extracted from Y. enterocolitica [25]. Considering common cross-reactions with other members of Enterobacteriaceae, such as Morganella morganii and Salmonella spp., between Y. enterocolitica serotype 0:9 and Brucella suis, or Y. enterocolitica serotype O:3 and Borrelia burgdorferi, Chlamydia trachomatis and Rickettsia spp., it should be emphasized that serological diagnostics of yersiniosis is difficult [25]. The determination of the serologic group of the examined strains is usually performed using the slide agglutination test. Live bacterial cells from the 24-h-bloodagar-culture as an antigen and the sera for the somatic antigens are used. The cells of the tested strain are suspended in a drop of $0.85 \% \mathrm{NaCl}$ and placed on a glass slide, and then connected with a drop of serum placed nearby and mixed using a bacteriological oese. The occurrence of agglutination with one out of the tested sera after shaking for $1 \mathrm{~min}$ is considered as a positive result. In the case of lack of agglutination with any serum, the strain is regarded as being non-identified [21, 22, 23].

ELISAs designed to detect IgM, IgG and IgA antibodies against $Y$. enterocolitica are most often applied in the diagnostics of chronic forms of the disease. The presence of IgA has been detected for as long as 9-12 months (in the case of yersiniosis complicated with polyarthritis), whereas in the course of classic yersiniosis, serum antibodies persist only up to 3 months after cessation of gastrointestinal symptoms [25]. Literature reports indicate the possibility to apply indirect immunofluorescence test in the diagnostics of yersiniosis on biopsied material or in histopathological preparations [25].

In the diagnostics of $Y$. enterocolitica infections, biological methods such as provoked vomiting, skin tests or Chinese hamster oocyte $(\mathrm{CHO})$ cultures have been sporadically applied. Only suckling mouse bioassay using Y. enterocoliticasusceptible mouse lines and test on rabbit ligated intestinal loops have been employed to experimentally demonstrate the toxigenic potential of examined strains [41, 42].

Bacteriological investigations to isolate $Y$. enterocolitica strains and tests that identify the biotype and serotype of isolates are currently the basis of diagnostics. Unfortunately, their labour- and time-consuming nature and a lack of possibility to precisely determine whether a given strain is obviously pathogenic create many problems in the traditional diagnostic approach. It has been shown more than once that the strains classified as biotype 1A, commonly thought to be non-pathogenic, may be a causative agent of clinical yersiniosis $[6,13,14]$. The serotypic specification is also not an unambiguous indicator of pathogenicity; for instance, the serotype O:8 includes both environmental, nonpathogenic strains [43] which cause disease in humans [30, 31]. Therefore, the molecular methods, such as hybridization or polymerase chain reaction (PCR), including multiplex PCR and real-time PCR, are often used [21, 22, 23]. There is a variety of genes specific for Y. enterocolitica, such as ail, inv, yadA, yops, yst or virF, whose sequences are detected with PCR. Multiplex PCR seems to be particularly useful to demonstrate in one reaction the presence of several gene fragments typical of $Y$. enterocolitica and connected with pathogenicity $[38,42]$.
PCR with the analysis of increasing amounts of product in real time (real-time PCR) is the only quantitative method. It allows determination of the number of gene copies or the level of its expression, and may be used, for example, to verify the efficacy of treatment [44]. Real-time PCR is based on a classic PCR; however, thanks to fluorescent-labelled primers, molecular probes or intercalating dyes fluorescent in the presence of the amplicons, it is possible to detect and monitor the gain of the product amount in each cycle of the reaction. It then becomes unnecessary to carry out electrophoretic separation of a product in agarose gel with ethydium bromide, which shortens the total time of testing and reduces the risk of contamination. The possibility to monitor the gain of a product in each real-time PCR cycle improves the accuracy of the test and allows determination of the initial amount of genetic material used in the reaction [45]. According to the literature, the sensitivity of the method allows the detection of less than 5 copies of a gene in the cell, which can be applied to the analysis of trace amounts of materials obtained with biopsy or with laser capture micro-dissection (LCM). High sensitivity and specificity makes real-time PCR a very popular technique in biomedical studies. It is used in molecular diagnostics to detect different pathogens and allows quantitative determination of even a small number of specific nucleotide sequences, including Y. enterocolitica $[46,47,48]$. Real-time PCR is also applied to quantitatively measure the copies of a gene, transgene or viral/bacterial genomes, and the level of RNA expression in the cells and tissues [47]. In testing the level of expression, the first step involves the RNA isolation. Next, the isolated nucleic acid is transcripted on cDNA which is used during quantitative real-time PCR. Unfortunately, this type of study has not yet been conducted in Poland.

Real-time PCR is also ideal for detecting and analyzing mutations, including single nucleotide polymorphism (SNP). It very often replaces sequencing or restriction fragment length polymorphism (RFLP). A mutation is identified by analyzing the melting curve of an amplified product, generated during each experiment. Until recently, this kind of $Y$. enterocolitica examination was used only by BancerzKisiel et al. [49] to identify ymoA (Yersinia modulator) SNP, with the aim of evaluating their influence on the enterotoxic properties of Y. enterocolitica strains. No correlations were observed between enterotoxic properties and the presence of mutations in the $y m o A$ gene region of Y. enterocolitica strains isolated from both humans and pigs.

Proper diagnostics of yersiniosis gives the opportunity to introduce effective treatment. Yersiniosis appearing with mild diarrhea requires only symptomatic treatment without antibacterials. However, in other, more severe cases, specific therapy should be attempted. In vitro, Y. enterocolitica is usually sensitive to: piperacillin, third-generation cephalosporins, monobactams, carbapenems (imipenem), aminoglycosides, tetracyclines, chloramphenicol, sulfametoxasol potentiated with trimethoprim, and a new generation of fluoroquinolons $[25,50]$. These bacteria are resistant to: penicillins, ampicyllin, carbenicillin and first-generation cephalosporins. The result of antibiotic treatment depends on the form of yersiniosis. In general, the use of one antimicrobial drug is effective, although combined treatment is recommended, such as aminoglycosides with third-generation cephalosporins. The presence of $\beta$-lactamases that confer antimicrobial resistance of some pathogenic strains underscores the importance of Y. enterocolitica surveillance [51]. 


\section{CONCLUSIONS}

Y. enterocolitica is the causative agent of yersiniosis - a zoonosis with substantial importance to public health. The swine population as a reservoir of $Y$. enterocolitica plays an important role in the epidemiology of the disease. Food products containing pork or pork-derived ingredients should be subjected to sanitary control. Considering the fact that insufficiently thermally processed pork is the main source of infection for humans, public information campaigns are an important element of the preventive measures against $Y$. enterocolitica infections. Yersiniosis usually appears in children as gastrointestinal disturbances, whereas in adults it is manifested as a pseudo-appendicitis form. Extra-enteric forms of yersiniosis are rare, the bacteria have been isolated in Reiter's syndrome, erythema nodosum or reactive polyarthritis. Diversified symptoms hinder clinical diagnostics and laboratory investigations are necessary. Classical bacteriological methods and standard procedures used to Y. enterocolitica classification as pathogenic do not take into account the new aspects of the pathogenesis of yersiniosis. The examples are biotype 1A strains, commonly regarded as non-pathogenic, although they are increasingly often isolated from clinical cases of yersiniosis. Molecular methods seem much more effective and accurate in the diagnostic. New diagnostic tools, such as real-time PCR, allow not only qualitative examination, but also quantitative evaluation of genes expression level or single nucleotide polymorphism detection. The State Sanitary Inspection responsible for the supervision of human infectious diseases in Poland constantly monitors the epidemiologic situation, including that of yersiniosis. Due to the fact that yersiniosis is a zoonosis, the State Sanitary Inspection representatives should stay in permanent contact with the State Veterinary Inspection by exchanging information on the current epidemiologic and epizootic situation. Considering the lack of medical prevention of the disease, sanitary and hygienic conditions in slaughterhouses, and public information campaigns are crucial, according to the World Health Organization. Informing and educating society on the need to follow basic hygiene rules, especially in contact with food, is an essential measure in preventing the spread of factors which are the causative agents of gastrointestinal infections, including Y. enterocolitica.

\section{Acknowledgements}

This study was supported by the National Science Centre (NCN, Grant No. N N308 609338).

\section{REFERENCES}

1. European Food Safety Authority. The European Union Summary Report on Trends and Sources of Zoonoses, Zoonotic Agents and Food-borne Outbreaks in 2011. EFSA Journal. 2013; 11: 3129-3379. doi: 10.2903/j.efsa.2013.3129.

2. Furman S, Sadkowska-Todys M. Yersiniosis in Poland in 2011. Przegl Epidemiol. 2013; 67: 221-225.

3. Kamińska S, Sadkowska-Todys M. Yersiniosis in Poland in 2012. Przegl Epidemiol. 2014; 68: 235-238.

4. Huovinen E, Sihvonen LM, Virtanen MJ, Haukka K, Siitonen A, Kuusi M. Symptoms and sources of Yersinia enterocolitica-infection: a casecontrol study. BMC Infect Dis. 2010; 10: 122.

5. Bucher M, Meyer C, Grötzbach B, Wacheck S, Stolle A, FredrikssonAhomaa M. Epidemiological Data on Pathogenic Yersinia enterocolitica in Southern Germany During 2000-2006. Foodborne Pathog Dis. 2008; 5: 273-280.

6. Sabina Y, Rahman A, Ramesh ChR, Montet D. Yersinia enterocolitica: Mode of Transmission, Molecular Insights of Virulence, and Pathogenesis of Infection. J Pathog. 2011; doi: 10.4061/2011/429069.

7. Neubauer H, Aleksic S, Hensel A, Finke EJ, Meyer H. Yersinia enterocolitica $16 \mathrm{~S}$ rRNA gene types belong to the same genospecies but form three homology groups. Int J Med Microbiol. 2000; 290: 61-64.

8. Bhagat N, Virdi JS. Distribution of virulence-associated genes in Yersinia enterocolitica biovar 1A correlates with clonal groups and not the source of isolation. FEMS Microbiol Lett. 2007; 266: 177-183.

9. Batzilla J, Heesemann J, Rakin A. The pathogenic potential of Yersinia enterocolitica 1A. Int J Med Microbiol. 2011; 301(7): 556-561.

10. Gierczyński R. Evaluation of the usefulness of selected virulence markers for identification of virulent Yersinia enterocolitica strains. II. Genotypic markers associated with the pYV plasmid. Med Dośw Mikrobiol. 2000; 52: 35-49.

11. Gierczyński R. Evaluation of the usefulness of selected virulence markers for identification of virulent Yersinia enterocolitica strains. III. Chromosome markers of virulence. Med Dośw Mikrobiol. 2000; 52: 51-65.

12. Tennant SM, Skinner NA, Joe A, Robins-Browne RM. Homologues of Insecticidal Toxin Complex Genes in Yersinia enterocolitica Biotype $1 \mathrm{~A}$ and Their Contribution to Virulence. Infect Immun. 2005; 73: 6860-6867.

13. Singh I, Virdi JS. Production of Yersinia stable toxin (YST) and distribution of $y$ st genes in biotype 1A strains of Yersinia enterocolitica. J Med Microbiol. 2004; 53: 1065-1068.

14. Ramamurthy T, Yoshino KI, Huang X, Balakrish Nair G, Carniel E, Maruyama T, Fukushima H, Takeda T. The novel heat-stable enterotoxin subtype gene $(y s t B)$ of Yersinia enterocolitica: nucleotide sequence and distribution of the yst genes. Microb Pathog. 1997; 23: 189-200.

15. Kuehni-Boghenbor K, On SLW, Kokotovic B, Baumgartner A, Wassenaar TM, Wittwer M, Bissig-Choisat B, Frey J. Genotyping of Human and Porcine Yersinia enterocolitica, Yersinia intermedia, and Yersinia bercovieri Strains from Switzerland by Amplified Fragment Length Polymorphism Analysis. Appl Environ Microbiol. 2006; 6: 4061-4066.

16. Fosse J, Seegers H, Magras C. Prevalence and Risk Factors for Bacterial Food-Borne Zoonotic Hazards in Slaughter Pigs: A Review. Zoonoses Public Health 2009; 56: 429-454.

17. Laukkanen-Ninios R, Fredriksson-Ahomaa M, Korkeala H. Enteropathogenic Yersinia in the Pork Production Chain: Challenges for Control. Compr Rev Food Sci F. 2014; 13: 1165-1191.

18. Swaminathan B, Harmon MC, Mehlman IJ. Yersinia enterocolitica. J Appl Bacteriol. 1982; 52: 151-183.

19. Francis DW, Spaulding PL, Lovett J. Enterotoxin production and thermal resistance of Yersinia enterocolitica in milk. Appl Environ Microbiol. 1980; 40: 174-176.

20. Handbook of Foodborne Pathogenic Microorganisms http:// www.fda.gov/downloads/Food/FoodSafety/FoodborneIllness/ FoodborneIllnessFoodbornePathogensNaturalToxins/BadBugBook/ UCM297627.pdf (access: 2014.11.03).

21. Bancerz-Kisiel A, Szczerba-Turek A, Platt-Samoraj A, Socha P, Szweda W. Application of multiplex PCR for the evaluation of the occurrence of ail, $y s t A$ and $y s t B$ genes in Yersinia enterocolitica strains isolated from wild boars (Sus scrofa). Bull Vet Inst Pulawy. 2009; 53: 351-355.

22. Bancerz-Kisiel A, Szczerba-Turek A, Lipczyńska K, Stenzel T, Szweda W. Bioserotypes and virulence markers of Yersinia enterocolitica strains isolated from mallards (Anas platyrhynchos) and pheasants (Phasianus colchicus). J Food Prot. 2012; 75: 2219-2222.

23. Bancerz-Kisiel A, Szczerba-Turek A, Platt-Samoraj A, Socha P, Szweda W. Roe deer (Capreolus capreolus) and red deer (Cervus elaphus) as an environmental reservoir and potential source of Yersinia enterocolitica infection for humans. Pol J Vet Sci. 2014; 17: 315-319.

24. Carter JE, Nelson JJ. Four-month-old female infant with bloody diarrhea. Yersinia enterocolitica infection. Pediatr Infect Dis J. 2007; 26: 664-665.

25. Jagielski M, Rastawicki W, Kałużewski S, Gierczyński R. Yersiniosis unappreciated infectious disease. Przegl Epidemiol. 2002; 56: 57-64.

26. Mielczarek P, Bagłaj M. Jersinioza - rzadko rozpoznawana choroba układu pokarmowego. Gastroenterologia Polska 2004; 11: 69-74 (in Polish).

27. Rowicka G. Bóle brzucha sugerujące zapalenie wyrostka robaczkowego spowodowane zakażeniem bakterią Yersinia u pięciorga dzieci - opis przypadków. Ped Współcz Gastroent, Hepat i Żyw Dziecka. 2005; 7 (3): 235-237 (in Polish). 
28. Garwolińska H. Reaktywne zapalenie stawów wywołane pałeczkami Yersinia enterocolitica. Klinika 1994; 12: 16-18 (in Polish).

29. Wang Z, Zhang Q, Lu J, Jiang F, Zhang H, Gao L, Zhao J. Identification of outer membrane porin $\mathrm{f}$ protein of Yersinia enterocolitica recognized by antithyrotopin receptor antibodies in Graves' disease and determination of its epitope using mass spectrometry and bioinformatics tools. J Clin Endocrinol Metab. 2013; 95: 4012-4020.

30. Rastawicki W, Szych J, Gierczyński R, Rokosz N. A dramatic increase of Yersinia enterocolitica serogroup O:8 infections in Poland. Eur J Clin Microbiol Infect Dis. 2009; 28: 535-537.

31. Rastawicki W, Szych J, Rokosz N, Zacharczuk K, Gierczyński R. Seasonality of Yersinia enterocolitica bioserotype 1B/O:8 infections in Poland. Epidemiol Infect. 2013; 141(10): 2039-2042.

32. Stroel E, Heesemann J, Mayer G, Peters J, Müller-Weihrich S, Emmerling P. Bacteriological and serological findings in a further case of transfusion-mediated Yersinia enterocolitica sepsis. J Clin Microbiol. 2000; 38: 2788-2790.

33. Grigull L, Linderkamp C, Sander C, Schmid H, Mutschler U, Welte K, Beilken A. Multiple spleen and liver abscesses due to Yersinia enterocolitica septicemia in a child with congenital sideroblastic anemia. J Pediatr Hematol Oncol. 2005; 27: 624-626.

34. Tennant SM, Grant TH, Robins-Browne RM. Pathogenicity of Yersinia enterocolitica biotype 1A. FEMS Microbiol Lett. 2003; 38: 127-137.

35. Ratnam S, Mercer E, Picco B, Parsons S Butler R. A nosocomial outbreak of diarrhoeal disease due to Yersinia enterocolitica serotype 0:5, biotype 1. J Inf Dis. 1982; 145: 242-247.

36. Greenwood MH, Hooper WL. Excretion of Yersinia spp. associated with consumption of pasteurized milk. Epidemiol Infect. 1990; 104: 345-350.

37. McNally A, Dalton T, La RagioneRM, Stapleton K, Manning G, Newell DG. Yersinia enterocolitica isolates of differing biotypes from humans and animals are adherent, invasive and persist in macrophages, but differ in cytokine secretion profiles in vitro. J Med Microbiol. 2006; 55: $1725-1734$

38. Kot B. Fenotypowe i genotypowe cechy pałeczek Yersinia enterocolitica oraz ich znaczenie w wykrywaniu potencjalnie chorobotwórczych szczepów. Rozprawa naukowa nr 85. Wydawnictwo Akademii Podlaskiej, 2006 (in Polish).

39. Platt-Samoraj A, Szweda W, Siwicki AK. Wpływ zakażeń Yersinia enterocolitica psów i kotów na występowanie jersiniozy u człowieka. Med Weter. 2000; 56(6): 379-381 (in Polish).

40. PN-EN ISO 10273:2005, 2005. Microbiology of food and animal feed. Horizontal method for the detection of Microbiology of food and animal feed. Horizontal method for the detection of presumably pathogenic Yersinia enterocolitica. Polish Committee for Standardization: Polish Norm - European Norm (with appendix PN-EN ISO 10273:2005/Ap1, 2005; PN-EN ISO 10273:2005/Ap2, 2006).

41. Pimbley DW, Patel PD. A review of analytical methods for the detection of bacterial toxins. Symp Ser Soc Appl Microbiol. 1998; 27: 98-109.

42. Bancerz-Kisiel A, Szczerba-Turek A, Platt-Samoraj A, Szweda W. Distribution of the $y m o A$ and $y s t A$ genes and enterotoxins Yst production by Yersinia enterocolitica strains isolated from humans and pigs. Pol J Vet Sci. 2012; 15: 609-614.

43. Wang X, Qiu H, Jin D, Cui Z, Kan B, Xiao Y, et al. O:8 serotype Yersinia enterocolitica strains in China. Int J Food Microbiol. 2008; 125: 259-266.

44. Böckelmann U, Dörries HH, Neus Ayuso-Gabella M, Salgot de Marçay M, Tandoi V, Levantesi C. Quantitative PCR Monitoring of Antibiotic Resistance Genes and Bacterial Pathogens in Three European Artificial Groundwater Recharge Systems. Appl Environ Microbiol. 2009; 75(1): 154-163.

45. Najdenski H, Heyndrickx M, Herman L, Werbrouck H, Van Coillie E. Quantification of Yersinia enterocolitica in raw milk using Qpcr. Vet Microb. 2012; 160(3-4): 428-434.

46. Lambertz ST, Nilsson C, Hallanvuo S, Lindblad M. Real-Time PCR Method for Detection of Pathogenic Yersinia enterocolitica in Food. Appl Environ Microbiol. 2008; 74(20): 6060-6067.

47. Orłowska A, Smreczak M, Trębas P, Żmudziński JF. Comparison of Real Time PCR and heminested RT-PCR methods in the detection of rabies virus infection in bats, and terrestrial animals. Bull Vet Inst Pulawy. 2008; 52: 313-318.

48. Wolffs P, Knutsson R, Norling B, Radstrom P. Rapid Quantification of Yersinia enterocolitica in Pork Samples by Novel Sample Preparation Method, Flotation, Prior to Real-Time PCR. J Clin Microbiol. 2004; 42(3): 1042-1047.

49. Bancerz-Kisiel A, Lipczyńska K, Szczerba-Turek A, Gospodarek E, Platt-Samoraj A, Szweda W. The use of the HRM method for identifying possible mutations in the $y m o A$ gene region and evaluating their influence on the enterotoxic properties of $Y$. enterocolitica strains. BMC Vet Res. 2014; 10: 207-211.

50. Baumgartner A, Küffer M, Suter D, Jemmi T, Rohner P. Antimicrobial resistance of Yersinia enterocolitica strains from human patients, pigs and retail pork in Switzerland. Int J Food Microbiol. 2007; 115: 110-114.

51. Galindo CL, Rosenzweig JA, Kirtley ML, Chopra AK. Pathogenesis of Y. enterocolitica and Y. pseudotuberculosis in Human Yersiniosis. J Pathog. 2011; doi: 10.4061/2011/182051. 